\title{
Optimization of a transient antibody expression platform towards high titer and efficiency
}

\author{
Elizabeth Greene ${ }^{1}$, Ninkka Tamot ${ }^{1}$, Daniela Cazacu ${ }^{1}$, Douglas Gebhard ${ }^{1}$, Steven \\ Castellano $^{1}$, Anthony Kronkaitis ${ }^{1}$, Jon Reed ${ }^{1}$, Paul Mason ${ }^{1}$, Lore Florin ${ }^{1}$, Nicholas Rossi ${ }^{1}$, \\ Anthony Lauer ${ }^{1}$, Laura Juckem ${ }^{1}$, Andrew Nixon ${ }^{1}$, Till Wenger ${ }^{2}$, and Saurabh Sen ${ }^{3}$ \\ ${ }^{1}$ Affiliation not available \\ ${ }^{2}$ Boehringer Ingelheim \\ ${ }^{3}$ Boehringer Ingelheim Corp USA
}

June 3, 2020

\begin{abstract}
Transient gene expression (TGE) using mammalian cells is an extensively used technology for production of antibodies and recombinant proteins and has been widely adapted by both academic and industrial labs. Chinese Hamster Ovary (CHO) cells have become one of the major work horses for TGE of recombinant antibodies due to their attractive features: post-translational modifications, adaptation to high cell densities, and use of serum-free media. In this study, we describe the optimization of parameters for TGE for antibodies from CHO cells. Through a matrix evaluation of multiple factors including inoculum, transfection conditions, amount and type of DNA used and post-transfection culture conditions, we arrived at an optimized process with higher titer and reduced costs and time, thus increasing the overall efficiency of early antibody material supply. We investigated the amount of coding DNA and the influence of size of the transfection complex on the in vitro efficiency of the transfection. Generation of the transfection complex in serum-free medium leads to the prompt formation of an optimal-sized polyplex, and is independent of the relative amount of coding DNA used for a successful transfection outcome.
\end{abstract}

\section{Hosted file}

LEX Manuscript_fugures_BTJ submission.docx available at https://authorea.com/users/329430/ articles/456439-optimization-of-a-transient-antibody-expression-platform-towards-hightiter-and-efficiency 